\title{
Televisão e Formação Académica dos Adolescentes: Um Estudo de Caso num Bairro de Luanda ${ }^{1}$
}

\author{
Adérito Manuel \\ Sociólogo, licenciado em Sociologia no Instituto Superior de Ciências da \\ Educação (ISCED) de Luanda da Universidade Agostinho Neto. É docente desta \\ instituição, assistente estagiário, colocado no Departamento de Ciências Sociais. \\ E-mail: Aderito27@yahoo.com.br
}

\begin{abstract}
Resumo:
A escola e a televisão são dois dos mais influentes agentes de socialização para os adolescentes. Em Luanda tem aumentado o número de pessoas e instituições que têm tido cada vez mais acesso, quer por cabo, quer por antena parabólica, a canais de televisão emitidos de diferentes realidades socioculturais e com diversificada programação. Assim, a televisão parece se tornar, cada vez mais, num poderoso concorrente que veicula valores, quantas vezes perversos, em relação ao que é transmitido pela escola mas também pode tornar-se num potencial complemento ou aliado desta última para a formação académica dos adolescentes em função das escolbas que possam fazer dos programas de televisão que tenham conteúdo que aprendem na escola. Deste modo, que articulação têm a televisão e a escola para a formação dos adolescentes? É essa a principal questão por nós discutida.

A nossa comunicação é basead numa pesquisa que realizámos num bairro de Luanda. Pretende demonstrar que esta articulação tem sido fraca para os adolescentes do bairro que foi objecto do estudo, por isso, os adolescentes têm boas razões para prestarem mais atenção aos programas de entretimento do que aqueles que têm carácter académico e científico.
\end{abstract}

Palavras-chaves: televisão, formação académica, adolescentes, racionalidades e capital cultural

1 Comunicação apresentada no $1^{\circ}$ Congresso Africano de Sociologia realizado em Julho de 2007, na Universidade de Rhodes, África do Sul. 


\section{Introdução}

A partir da década de 1930, os meios de comunicação de massa entram no centro das preocupações das grandes firmas que as utilizam, da classe política, da intelectualidade e da opinião pública. Estes múltiplos interesses incentivaram o surgimento de um dos mais inovadores ramos da sociologia americana: a sociologia dos meios de comunicação de massa [Morin 1998: 250].

A adolescência surge como classe de idade em meados do sec. XX sob estimulação do capitalismo do espectáculo imaginário [id: 205]. Nesta comunicação consideramos adolescentes segundo Gauquelin et al [1980: 18] que postulam que é uma faixa etária que vai dos 18 aos 18 anos para as meninas e dos 14 aos 20 anos para os rapazes².

No dia-dia de Luanda tem havido muitas maneiras de agir, sentir, fazer e estar dos adolescentes que, aparentemente, têm alguma relação com o que é veiculado pela televisão. Por outro lado, sabe-se, que de segunda à sexta-feira, durante 9 meses, uma boa parte dos adolescentes frequenta uma instituição escolar. Neste âmbito, sendo dois agentes de socialização que têm grande influência na vida desta categoria social, nesta comunicação pretendemos reflectir o contributo que a televisão (enquanto meio de difusão massiva e de ensino) pode dar para a formação académica dos adolescentes angolanos face o incremento de canais que são emitidos para Luanda a partir do estrangeiro.

Analisar a relação entre a televisão e a escola na formação académica dos adolescentes, inscreve-se no âmbito da sociologia dos meios de comunicação de massa e da educação. Praticamente, na sociedade angolana, existem muito poucas pesquisas sociológicas sobre a matéria, e outras que são realizadas sobre a audiência de media em Luanda ${ }^{3}$.

O impacto dos meios de comunicação de massa, mas concretamente da televisão, na maneira de estar, sentir e fazer dos adolescentes, devia ser uma preocupação dos especialistas de ciências sociais. Hoje a televisão é um canal fortemente socializador, faz com que as crianças penetrem num mundo dos adultos muito cedo, tomando conhecimento dos seus valores, adquirindo ideias, crenças e comportamentos que as faz se tornarem adultas muito cedo [Carpelli 1986: 93].

Sendo este meio um dos mais influentes agentes de socialização desta categoria social, e com a difusão cada vez mais de canais emitidos a partir de realidades socio-culturais diferentes da sociedade angolana, o interesse devia ser maior.

Esta abordagem, de forma descritiva e analítica, tenta reflectir o fenómeno, a luz dos conceitos de racionalidade de Boudon e de capital de Bourdieu.

2 Pelo que temos estado a observar no quotidiano, esta definição nos parece estar próxima da realidade luandense.

3 Em 2002 Paulo de Carvalho realizou uma pesquisa sobre audiência de media em Luanda, em que apresenta um quadro de preferências a diferentes órgãos de comunicação de massas diferentes géneros de programas, em função de características sociológicas como a idade, sexo, o grau de instrução, a ocupação socioprofissional entre outras. Uma das suas conclusões é que quanto mais jovens os teles pectadores assistiam com mais tempo e regularidade os programas de televisão. 


\section{Notas sobre a trajectória da televisão em Angola}

$\mathrm{Na}$ Angola colonial, apesar das resistências do Governo português e da Rádio-Televisão Portuguesa - RTP, a televisão começa a dar os primeiros passos em Benguela na década de 1960, por iniciativa de António Freire e Franklin Barbosa, com as primeiras emissões a serem feitas em circuito fechado [Coelho 1999: 145]. Entre 1970 e 1971, os Estúdios Norte realizaram experiências de transmissão do programa "Café a Noite" da Rádio Oficial de Angola nas cidades de Luanda e Malanje, respectivamente [antónio 2003: 142]. Em 1973, é inaugurada a Televisão de Angola - TVA, uma estação comercial, que emitiu para uma parte de Luanda por cabo, com emissões de três horas diárias [Coelho id: 146]. A RTP, antes de 25 de Abril de 1974, pretendeu criar a Rádio-Televisão Portuguesa de Angola - RTPA, plano que foi interrompido devido a descolonização. Os meios técnicos serviram para a Televisão Popular de Angola - TPA [Coelho id: 146], que começou a emitir a 18 de Outubro de 1975. Com a mudança social que afectou estrutural e funcionalmente vários campos (político, económico, cultural e social) ocorrida após os "Acordos de Bicesse", de 31 de Maio de 1991, a televisão passa a ser denominada por Televisão Pública de Angola, embora a sigla se mantenha. Desde a independência até a presente data, é o único canal nacional de emissão que tenta que ao mesmo tempo prestar um serviço público e comercial [António id: 144-146]. Foi criado um segundo canal em 2000.

A partir da década de 1990, começaram a expandir-se as antenas parabólicas e o acesso por cabo que emitem canais de televisão estrangeiros, maioritariamente oriundos do Ocidente. Estas tecnologias parecem estar mais acessíveis e atraentes aos cidadãos em termos de custo e programação. Segundo Mateus [2006], em Angola, a elevisão não está a ser inspirada pelo projecto europeu de transformá-la num meio de informação, formação e recreação mas sim foi ulrapassada pela lógica utilitarista americana ${ }^{4}$.

\section{Abordagens sobre a articulação entre televisão e a escola}

A nossa comunicação tem a ver com a relação entre a televisão e a formação académica dos adolescentes, embora a maior parte das ideias que traremos de seguida digam mais respeito a relação entre a escola e a televisão, que é o mais corrente os investigadores tratarem. Pensamos que, para os nossos propósitos, o conceito de formação académica é mais abrangente. No nosso entender, a formação académica inclui, naturalmente, o que se aprende na escola e também outras experiência e conteúdos que os individuos aprendem e interiorizam fora do contexto escolar e que possam servir de complemento

4 Para Balle e Cazeneuve [s/d: 143] as televisões americanas aderem a ideologia do quantitativo, segun do o qual a quantidade de programas propostos define a qualidade do serviço que se presta. Na crise geral da sociedade, surge a "psicose do número", a uniformização dos gostos e a influência nefasta da televisão na criança. 
e aprofundamento dos conhecimentos necessários a sua formação académica.

A escola e a sociedade são duas instituições cujo impacto nos adolescentes na sociedade continua a ser objecto de vários debates.

Cada sociedade tem a sua escola, concebida em função da sua cultura, estrutura económica, ambições técnicas e científicas. É um produto das classes que detém o poder de governar e conservar os valores que caracterizam e reflectem a imagem da sociedade, dai que se diga "tal escola tal sociedade" [Desbordes 1977: 21].

Quase um terço da vida de um adolescente é feito na escola. Esta, através da sua estrutura e agentes, influencia o seu comportamento e sucesso escolar [Fenwick e Smith 1995: 151]. Para certo grupo de jovens, a escola é um local de aprendizagem e trocas simbólicas [Schmidt 1993: 277]. Segundo Pierre Emanuel [1997: 65], a escola é um local onde se forma a personalidade do adolescente, de relação aonde reproduzem uma certa imagem da realidade social tal como a vivem ou pressentem.

Segundo Bourdieu [1999: 34], a televisão é um meio de comunicação muito pouco autónomo, devido a imposições que têm a ver com as relações sociais entre os jornalistas, a concorrência, as relações de convivência, baseadas nos interesses ligados ao campo de produção simbólica e pelo facto dos jornalistas terem diferenças quanto as suas origens sociais, a sua formação e outras caracteristicas sociológicas.

A televisão, além ser um meio de socialização onde podem ser pregados os valores dos vários grupos e instituições sociais, também é em si um valor. "A televisão adquiriu um poder demasiado vasto no seio da democracia, é o mais importante de todos, como se tivesse substituido a voz de Deus" [Popper e Condry 1995: 30].

As pessoas que se deixam facilmente influenciar pela televisão, é porque nem sempre possuem maturidade e formação suficientes para distinguir a ficção e a realidade [id: 28]. Muitos adolescentes refugiam-se a televisão como desculpa para não realizarem os trabalhos de casa, para não participarem das actividades sociais e como indício de não estarem motivados para estudarem [Fenwick e Smith 1999: 116]. No entanto, antes de entrarem para a escola, muitas crianças já levam consigo conhecimentos que aprendem através da televisão [Freixo 2002: 49]. Quanto mais tempo o telespectador estiver a assistir televisão, mais sofre a sua influência independentemente dos conteúdos dos programas [Popper e Coundry id: 38]. Bluwal [1977: 48-52] entende que a televisão pode contra bater o esforço positivo da escola em relação às pessoas. A televisão não transmite totalmente a realidade, pois rodeia e isola determinados aspectos da vida. Toda a gente que faz televisão devia ter consciência do papel de educar que têm pelo facto de ser vista por muitas crianças e adolescentes. Muitos ignoram os efeitos do que produzem no consciente e inconsciente das pessoas [Popper e Coundry id: 26].

Morin [1998: 125] postula que pedagogos e professores não têm conseguido enfrentar a cultura difundida pelos meios de comunicação de massa, porque sabem que os alunos preferem a televisão aos seus deveres. Outrossim, para Freixo [2002: 496] os jovens preferem os programas recreativos, a seguir os desportivos, os de informação e de cultura. 
Segundo o Relatório "Educação um Tesouro a Descobrir" da Comissão Internacional para a Educação da UNESCO - adiante RCIEU [1996: 99] existia contradição entre a televisão e a escola: a televisão era acusada pelos professores de estar a promover um "mínimo denominador comum cultural", de reduzir o tempo dedicado a reflexão e a leitura impondo imagens de violência e de especulação das emoções; e os defensores dos meios de comunicação de massa acusavam a escola de demasiado conservadorismo e imobilismo, transmitia saberes com métodos antiquados que provocavam a desmotivação da aprendizagem. Segundo Anderson [apud Giddens 2000: 448] nem sempre se pode associar entretimento e desempenho escolar. A televisão e os jogos somente intensificam o desinteresse pelas actividades escolares se estas forem desagradáveis. Para Freixo [2002: 506], os jovens não são receptores passivos mas sim activos porque codificam, armazenam, interpretam, seleccionam, distorcem e recolhem os conteúdos televisivos que lhes parecem importantes para o seu comportamento, integração escolar e desempenho escolar.

Popper e Coundry [apud Oliveira 2002: 32 à 67] que se a escola fosse mais eficaz, o poder da televisão seria menor, mas a escola não deve levar acabo a sua acção ignorando a televisão. Como poderoso currículo paralelo, a televisão devia integrar conteúdos escolares e a escola devia reflectir sobre o seu atraso em termos de veiculação da informação. O RCIEU [1996: 99], neste âmbito, exemplifica o Japão onde 90\% das escolas tinham televisão como instrumento pedagógico pois embora a televisão não tenha objectivo de interesse educativo, tem um grande poder de sedução. Aconselha a escola a produzir conhecimentos que sejam veiculados pela rádio e pela televisão, pois há necessidade dos professores formarem os alunos para que tenham uma leitura crítica sobre os programas de televisão. Ao invés da escola agir como se a televisão não existisse, deveria propor que as crianças discutissem os conteúdos dos programas de televisão [Popper e Coundry 1995: 62]. Para Bluwal [1977: 48-52] a interacção entre a escola e a televisão é uma nova fase da educação. Como meio de educação formal, os professores devem despertar curiosidade, desenvolver a autonomia, estimular o rigor intelectual e, assim, criar condições para o sucesso da educação formal e não formal. Deste modo, a escola torna-se num local mais atraente e merecido para a sociedade de informação, adaptado a realidade socio-cultural de cada colectividade [RCIEU 1996: 131-132]. A televisão educativa, que veicula vários cursos, como a educação a distância ou "escola pelo ar" são boas propostas nesta interacção [Oliveira 2002: 80].

Pode depreender-se que os adolescente optam mais pelos programas recreativo do que propriamente os programas académicos e científicos emitidos pela televisão. Isto reservam a escola que é a instituição vocacionada para o ensino e a aprendizagem sistemática, pedagógica e científica do conhecimento. Seria interessante que os valores transmitidos pelos agentes de socialização em referência não se contradizessem nos seus aspectos essenciais. Devia haver mais articulação entre a escola e a televisão, propondose por exemplo debates em relação aos conteúdos dos programas de televisão. 
Actualmente, em relação a socialização das novas gerações, a família e a escola são duas instituições que estão cada vez mais a perder impacto à favor, principalmente, da televisão, embora esta última esteja concebida para partir do pressuposto que as pessoas tenham maturidade suficiene para escolherem os conteúdos que pretendem receber [Freixo, 2002: 52]. Para a realização desta pesquisa, partimos da hipótese que quanto mais tempo os adolescentes se dedicam a assistir programas de televisão, mais probabilidade têm de terem baixo rendimento escolar, porque se preocupam mais em assistir programas de entretimento e pouca atenção prestam a aqueles que têm pendor científico e pedagógico. Isto sucede porque os professores e encarregados de educação não têm lhes incentivado a assistir programas com pendor científico e pedagógico e a ter uma postura crítica em relação aos programas difundidos pela televisão.

\section{O Estudo de Caso}

\subsection{Metodologia e inquiridos}

Realizámos uma pesquisa junto de 100 adolescentes num bairro de Luanda. Em cada residência conversámos apenas com um indivíduo pertencente a esta categoria social. A recolha de dados foi feita no período entre 26 de Dezembro de 2003 e 5 de Janeiro de $2004^{5}$, em 8 ruas, onde conversámos em cada uma delas, com um máximo de 10 adolescentes, o que perfaz um total de 80 . Os restantes respondentes, cerca de 20 , foram consultados numa área onde residem pessoas deslocadas e de muito baixo rendimento, com residências, em boa parte dos casos, construídas com material impróprio como chapas de zinco, no papel de paredes que deviam ser edificadas com blocos, tijolos ou outro material adequado. Nesta última área é que tivemos maior dificuldade de conversar com os encarregados de educação, pois muitos deles, têm grau de instrução académica muito baixo, não acompanhavam a programação da televisão e, por isso, pouco tinham a comentar em relação as questões apresentadas, ainda que fosse por conversa informal. A estas dificuldades acrescentam-se outras como indisponibilidade, desinteresse e o receio em contribuir por parte de alguns encarregados de educação. Mesmo assim, ultrapassámos a nossa previsão inicial, pois pretendíamos realizar a nossa pesquisa junto de 50 encarregados de educação, mas atingimos 55, o que demonstra o interesse pela temática. Não tivemos grandes problemas em convencer os adolescentes a participarem e a responderem ao questionário. Manifestaram-se sempre muito curiosos em compreender a importância e os objectivos do nosso estudo.

Para os adolescentes utilizamos uma entrevista estruturada através de um formulário ${ }^{6}$

5 Antes da definitiva recolha de dados, realizamos um pré-teste com 15 adolescentes e 6 encarregados de educação duma escola, que nos permitiu corrigir e elaborar definitivamente os questionários.

6 Segundo Marina Marconi e Eva Maria Lakatos [1986: 56 à 108], o formulário é um questionário em que o próprio investigador o preenche. 
por ser, segundo as nossas pesquisas exploratórias, das técnicas mais adequadas para pesquisa do género porque uma boa parte da população luandense tem fraca capacidade de literácia, sente-se inibida perante um aparelho audiovisual e não está habituada a lidar com pesquisas sociais. Para a maioria dos encarregados de educação foram utilizados inquéritos preenchidos pelos próprios, e uma minoria que se recusou a preencher foi também usado o formulario ${ }^{7}$.

Para a extracção da amostra, utilizamos as técnicas de amostragem não probabilística, objectiva e heterogénea. Segundo Marina Marconi e Eva Lakatos [1986: 47], a características principal das técnicas não probabilísticas é não fazerem recurso a formas aleatórias de selecção, o que faz não ser possível a aplicação de determinadas fórmulas estatísticas como por exemplo o cálculo do erro amostral. Segundo João Maroco [2003: 21-22] a amostragem objectiva é aquela que consiste em seleccionar subgrupos restritos que são mais receptivos aos objectivos do estudo. A amostragem heterogénea ou de diversidade é constituída de modo que todas as características, opiniões, atributos etc., estejam presentes na obra independentemente das proporções com que estas se encontram na população.

Com estas técnicas, fazemos uma abordagem quantitativa e qualitativa, pois apresentaremos estatisticamente os dados e também algumas opiniões, justificações e sugestões que foram dadas pelos adolescentes e os encarregados de educação.

\subsection{Características sócio-demográficas}

Nesta pesquisa, questionamos os adolescentes sobre determinadas características pessoais como a origem étnica dos encarregados de educação, ocupação sócio- profissional dos encarregados de educação, sexo dos encarregados de educação, idade, nível de acesso a televisão, nível académico, sexo dos adolescentes e condições de habitabilidade.

Os nossos entrevistados declararam que seus encarregados de educação têm origem etnolinguística ${ }^{8}:$ Ambundu - 73\%., Bakongo - 8\%, Tchokwe - 4\%, Ovimbundu - 2\% Outras - $3 \%{ }^{9}$ e não responderam $-11 \%$.

A maioria, cerca de 54\%, declarou serem os seus encarregados de educação do sexo masculino e os restantes, cerca de 46\%, declarou serem indivíduos do sexo oposto.

7 Sobre a vantagem e desvantagem do formulário, do inquérito e outras técnicas, vide Marina Marconi e Eva Maria Lakatos (1986) pp. 56 à 108.

8 No questionário, dado o desconhecimento que se tem do conceito, perguntamos sobre a província em que pertenciam os encarregados de educação. A partir das áreas geográficas indicadas, nos baseamos nos mapas etnolinguístico de Angola inseridos na obra de João Fernando e Zavoni Ntondo "Angola: Povos e Línguas" (2003), e fizemos a distribuição aqui apresentada. Claro que esta distribuição, even tualmente, poderá não ser totalmente certa, em função do questionamento que se faz ao critério lin guístico (vide por exemplo Kajibanga, 1998 e 2000).

9 Por não conhecermos bem a composição étnica das áreas indicadas, preferimos não tipificar as res tantes, pois poderíamos induzir por demais em erros quanto a origem étnica dos demais encarregados de educação.. 
Quanto a ocupação socio-profissional dos encarregados de educação, subdividimosas em 4 categorias: os funcionários de alto escalão, os funcionários de médio escalão, os funcionários de baixo escalão e os não funcionários, tendo como critérios a função e o tipo de profissão exercida no local de trabalho, independentemente de a exercer numa instituição pública, privada ou por conta própria ${ }^{10}$. Assim, ficaram distribuídos em $57 \%$ de funcionários de baixo escalão, $12 \%$ de funcionários de médio escalão, $1 \%$ de funcionários de alto escalão, sem ocupação socio- profissional $16 \%$ e sem dados ou respostas $11 \%$.

As condições de habitabilidade têm como indicadores o acesso a energia eléctrica, a dimensão da residência, o acesso a água potável e a propriedade da residência. Consideramos as condições de habitabilidade alta os que tinham uma residência de grande dimensão, acesso a água potável, residência própria ${ }^{11}$ e acesso regular de energia eléctrica $^{12}$. As condições de habitabilidade média aquelas que tinham pelo menos três valores médios de dois indicadores como por exemplo residência média, acesso irregular de energia eléctrica e o acesso a água potável pela canalização da residência. Os que foram considerados com condições de habitabilidade baixa são os demais com indicadores como residência de pequeno tamanho e sem acesso a energia eléctrica. Assim, os inquiridos ficaram distribuídos em $77 \%$ de pessoas que residem em condições de habitabilidade média, 21\% de pessoas com condições de habitabilidade baixa e 2\% de pessoas com condições de habitabilidade alta.

Em relação ao acesso à televisão: considerámos como indicadores a não existência em casa de um aparelho de televisor ou a existência de um televisor a preto e branco com apenas o canal nacional como sendo baixo, a existência em casa de pelo menos um aparelho de televisor a cores com a emissão da única televisão angolana como sendo médio, e consideramos aqueles que têm acesso em casa a canais de televisão estrangeiros (normalmente têm televisores a cores) como sendo alto. Assim 9\% são do nível baixo, $30 \%$ do nível alto e $61 \%$ do nível médio.

Em relação ao sexo dos adolescentes por nós inquiridos, $58 \%$ são do sexo masculino e $42 \%$ do sexo feminino.

A idade varia dos 12 aos 20 anos. A mediana foi de 16 anos, quer dizer que pelo menos

10 Na última categoria (os não funcionários) incluímos apenas aquelas pessoas que não exercem qualquer actividade rentável de momento, como por exemplo as domésticas, os reformados etc. Por exemplo um médico, engenheiro ou outro técnico superior independentemente da sua função no local de trabalho, é considerado, a partida, funcionário de médio escalão. Os funcionários de alto escalão são aqueles que ocupam uma função máxima nas instituições do Estado (Ministérios, Direcção geral ou de grandes empresas do sector público ou privados).

11 A propriedade de residência não foi um indicador que tenha exercido grande influência à medida que a maioria dos entrevistados tinham residencia própria. Mesmo tendo sido incluída no questionário, após ter analisado a questão, verificámos que pouca influência tinha este indicador para a definição das condições de habitabilidade no Bairro em que o estudo foi realizado.

12 Entendemos por acesso regular de energia eléctrica àquela que se obtém pela EDEL e por outras fontes alternativas, sem prejuizo da necessidade e vontade de assistir a programação da televisão. 
metade dos inquiridos tem até esta idade. A moda foi de pessoas com 18 anos, quer dizer, conversamos com maior frequência com pessoas desta idade. De seguida a tabela no 1 de distribuição de idades:

\section{Tabela no1 Adolescentes por idade}

\begin{tabular}{|c|c|}
\hline IDADE & FREQUÊNCIA \\
\hline 12 & 6 \\
\hline 13 & 10 \\
\hline 14 & 14 \\
\hline 15 & 9 \\
\hline 16 & 15 \\
\hline 17 & 17 \\
\hline 18 & 21 \\
\hline 19 & 4 \\
\hline 20 & 4 \\
\hline Total & $\mathbf{1 0 0}$ \\
\hline
\end{tabular}

O nível de ensino dos adolescentes varia entre iletrados e aqueles que já têm o Ensino Médio concluído: 43\% é de adolescente que concluiu o IIIo Nível, 21\% o IIo Nível, 19\% o Ensino Médio, 16\% o Io Nível e 1\% iletrados.

\subsection{Sobre a Televisão e formação académica}

O estudo inclui questões relativas a programas televisivos que sirvam para complementar os conhecimentos escolares, a comparação entre o tempo dedicado a assistir televisão e o tempo dedicado à resolução dos deveres escolares, a opinião e acompanhamento que os encarregados de educação fazem aos programas de televisão em função das notas dos seus educandos.

Uma das questões que fizemos é se os adolescentes têm hábito de assistir programas que sirvam para consolidarem os conhecimentos escolares. 67\% dos adolescentes respondeu que tem assistido a pelo menos um programa que tenha este fim e 33\% respondeu negativamente. Questionámos com que frequência assistiam a estes programas e analisamos a relação entre estes programas (que consolidam os conhecimentos escolares) e aqueles que os adolescentes indicaram como sendo os cinco programas de sua preferência.

Como se pode verificar na tabela 2 , dos 67 adolescentes que declaram assistir a programas que consolidam os conhecimentos escolares, 55,2\% declarou assistir uma vez ou outra, 40,3\% declarou que assiste sempre, 3\% declarou que assistiu uma única vez 
e $1,5 \%$ não tinha qualquer resposta para questão ${ }^{13}$. A tabela que se segue nos ilustra a distribuição de respostas em relação a questão:

Tabela no2 Adolescentes em função da assistência de programas que sirvam para consolidar os conhecimentos escolares

\begin{tabular}{|l|l|l|l|l|}
\hline Respostas & Frequência & $\begin{array}{l}\text { Frequência } \\
\text { Acumulada }\end{array}$ & Percentagens (\%) & $\begin{array}{l}\text { Percentagens } \\
\text { acumuladas }\end{array}$ \\
\hline Assisto sempre & 27 & 27 & 40,3 & 40,3 \\
\hline Assisto uma vez ou outra & 37 & 64 & 55,2 & 95,5 \\
\hline Assisti uma única vez & 2 & 66 & 3 & 98,5 \\
\hline Não sabe & 1 & 67 & 1,5 & 100,0 \\
\hline Total & $\mathbf{6 7}$ & & $\mathbf{1 0 0 , 0}$ & \\
\hline
\end{tabular}

Ainda em relação aos que declararam sim, em 53,7\% não é possível encontrar dos cinco programas por eles indicados como preferidos, pelo menos um dos programas que são por estes referidos como sendo aqueles que sirvam de consolidação dos conhecimentos escolares. Em 38,8\% já é possível encontrar esta relação, enquanto que em 7,5\% não temos qualquer dado, porque os respondentes alegaram terem se esquecido dos programas. A tabela 3 ilustra a distribuição desta relação:

Tabela 3 Relação entre programas indicados como preferidos e programas que sirvam para consolidar os conhecimentos escolares

\begin{tabular}{|l|l|l|}
\hline Relação & Frequência & Percentagem (\%) \\
\hline Sim & 26 & 38,8 \\
\hline Não & 36 & 53,7 \\
\hline Sem dados & 5 & 7,5 \\
\hline Total & $\mathbf{6 7}$ & $\mathbf{1 0 0 , 0}$ \\
\hline
\end{tabular}

Em relação à articulação entre a televisão, professores e alunos, quisemos saber se alguma vez um professor de uma determinada disciplina fez referência a algum programa de televisão que sirva para consolidar os conteúdos leccionados na sua disciplina ou de uma outra. Quanto a esta questão, verifica-se que 64\% declarou que sim, 34\% que não e 2\% não emitiu qualquer opinião sobre o assunto.

No que concerne à questão sobre o que os adolescentes pensam em relação à escola e à televisão, procuramos saber o que pensam que os seus amigos valorizam mais: a aprendizagem escolar ou a aprendizagem da televisão. 53\% declarou que os seus amigos

13 É preciso ter em atenção que as percentagens correspondem aos adolescentes que declararam ver programas que servem para consolidar conhecimentos escolares. 
e colegas valorizam mais o que aprendem pela televisão, $42 \%$ declarou que valorizam mais o que aprendem na escola e $5 \%$, apesar de todas as insistências, manteve-se indecisos. É a questão em que os adolescentes se mostraram mais divididos. Procuramos saber das razões que levavam uns e outros a pensarem de uma ou de outra forma. Vamos, seguidamente, apresentar, em síntese, as razões apontadas pelos adolescentes:

Dos que mais valorizam a televisão

- A maioria dos amigos não são muito ligados a escola, valorizam pouco os estudos, estão muito mais vezes a ver televisão e não levam muito em conta aquilo que os professores dizem.

- Porque só conversam sobre os filmes, as novelas e outros programas.

- A maneira de vestir é inspirada na televisão, o comportamento deles é muito inspirado no que vêem pela televisão.

- $\quad$ Porque são turistas ${ }^{14}$.

- Porque quando saem da escola, comentam mais sobre o que assistem pela televisão do que aquilo que aprendem na escola.

- Mais a televisão porque nem todos os amigos frequentam a escola.

- Há coisas que dão na escola e que também a televisão passa.

- Porque assistem a programas que apresentam exercícios e ensinam muitas boas coisas.

Dos que mais valorizam a escola

- Nas aulas valorizam mais aquilo que aprendem numa determinada disciplina.

- Conversam mais sobre o que aprendem na escola.

- Pelo facto de na escola haver sempre quem explica as coisas.

- Porque existem poucos canais de televisão educativos, a escola ensina a boa educação, esta serve para aprender.

- Têm o hábito de estudo em grupo, a escola tem muitas disciplinas que exigem muito estudo, ensina melhor que a televisão.

- Os pais aconselham a valorizar mais a escola porque esta é que garante o futuro e a televisão não.

- A televisão ensina muita coisa boa mas também muita coisa má.

- A televisão nem sempre transmite aquilo que o professor ensina; este último transmite melhor as coisas.

Em relação ao tempo diário que cada adolescente se dedica na resolução dos deveres

14 Turistas na linguagem dos estudantes em Luanda, quer dizer indivíduos que, mesmo tendo saído de casa para à escola, preferem faltar às aulas e ficarem na rua. 
escolares e o que dedicam a assistir televisão. Trata-se de uma questão, de alguma forma, de cálculo rápido. Mas, mesmo assim, somente dois dos inquiridos não tinham nenhuma ideia sobre o tempo que dedicam. Os que responderam disseram dedicar no total 75,3 horas diárias a assistir televisão porquanto para a resolução dos deveres escolares, dedicam cerca de um total de 23,5 horas. O tempo que os adolescentes declararam assistir televisão varia entre 0,3 e 12 horas, enquanto que o tempo dedicado a revisão e resolução dos deveres escolares varia entre 0 e 6 horas. Em relação a primeira situação, temos uma distribuição bimodal, 2 e 3 horas foram os tempos mais citados. No segundo caso, a moda foi de 1 hora. Em média, cada adolescente declarou dedicar 3,6 horas diárias a ver televisão e 1,8 horas a resolver e a rever os deveres escolares. A seguir as tabelas 4 e 5 sobre esta questão:

Tabela 4 Adolescentes em função das horas diárias que se dedicam a assistir televisão

\begin{tabular}{|l|l|l|l|l|}
\hline Horas & Frequência & $\begin{array}{l}\text { Frequência } \\
\text { Acumulada }\end{array}$ & Percentagem (\%) & $\begin{array}{l}\text { Percentagem } \\
\text { Acumulada }\end{array}$ \\
\hline 0.3 & 1 & 1 & 1,0204 & 1,0204 \\
\hline 0,5 & 3 & 4 & 3,0612 & 4,0816 \\
\hline 1 & 10 & 14 & 10,2041 & 14,2857 \\
\hline 1,5 & 5 & 19 & 5,1020 & 19,3877 \\
\hline 2 & 16 & 35 & 16,3265 & 35,7142 \\
\hline 2,5 & 5 & 40 & 5,1020 & 40,8162 \\
\hline 3 & 16 & 56 & 16,3265 & 57,1427 \\
\hline 3,5 & 1 & 57 & 1,0204 & 58,1631 \\
\hline 4 & 14 & 71 & 14,2857 & 72,4488 \\
\hline 5 & 7 & 78 & 7,1429 & 79,5917 \\
\hline 6 & 7 & 85 & 7,1429 & 86,7346 \\
\hline 7 & 8 & 93 & 8,1633 & 94,8979 \\
\hline 8 & 1 & 94 & 1,0204 & 95,9183 \\
\hline 9 & 1 & 95 & 1,0204 & 96,9387 \\
\hline 10 & 2 & 97 & 2,0408 & 98,9795 \\
\hline 12 & 1 & 98 & 1,0204 & 99,9999 \\
\hline Total & $\mathbf{9 8}$ & & $\mathbf{9 9 , 9 9 9 9}$ & \\
\hline
\end{tabular}


Tabela 5 Adolescentes em função das horas diárias que se dedicam a resolver os trabalhos escolares

\begin{tabular}{|l|l|l|l|l|}
\hline Horas & Frequência & $\begin{array}{l}\text { Frequência } \\
\text { Acumulada }\end{array}$ & Percentagens (\%) & $\begin{array}{l}\text { Percentagem } \\
\text { Acumulada }\end{array}$ \\
\hline 0 & 1 & 1 & 1,0 & 1,0 \\
\hline 0,2 & 1 & 2 & 1,0 & 2,0 \\
\hline 0,3 & 1 & 3 & 1,0 & 3,0 \\
\hline 0,5 & 14 & 17 & 14,3 & 17,3 \\
\hline 1 & 29 & 46 & 29,6 & 46,9 \\
\hline 1,5 & 5 & 51 & 5,1 & 52,0 \\
\hline 2 & 23 & 74 & 23,5 & 75,5 \\
\hline 3 & 14 & 88 & 14,3 & 89,8 \\
\hline 4 & 8 & 96 & 8,2 & 98,0 \\
\hline 5 & 1 & 97 & 1,0 & 99,0 \\
\hline 6 & 1 & 98 & 1,0 & 100,0 \\
\hline Total & 98 & & 100,0 & \\
\hline
\end{tabular}

Em relação aos encarregados de educação, pretendemos saber se a televisão influencia as notas de seus educandos, se têm tomado medidas especiais em relação ao tempo e regularidade de assistir televisão em função das notas, e como é que avaliavam as notas de seus educandos.

Quanto a questão relativa a influência da televisão nas notas dos educandos, 32,7\% dos encarregados de educação acha que não influencia, $21,8 \%$ acha que influencia pouco, $18,2 \%$ acha que influencia muito, $16,4 \%$ acha que influencia razoavelmente enquanto que $10,9 \%$ não emitiu qualquer opinião sobre o assunto.

Questionados se têm tomado medidas especiais, em relação ao tempo e regularidade de assistir televisão em função das notas, a maioria dos encarregados de educação, $76,4 \%$, respondeu que tem tomado este tipo de medidas enquanto que $23,6 \%$ respondeu negativamente. Pedimos aos que responderam positivamente que nos indicassem algumas medidas que têm estado a tomar. Em síntese são as seguintes:

- Evitar que assistam a televisão até muito tarde.

- Em tempo de aulas e sobretudo quando as notas estão baixas, restrição dos programas que se deve assistir e obrigação para se dedicarem mais aos estudos.

- Assistência de televisão somente após a resolução e revisão da matéria escolar.

- Conversação sobre a importância que se deve dar a programas de televisão educativos e não a filmes para adultos.

Última pergunta, relativa à questão académica, feita aos encarregados de educação, 
era para fazerem uma avaliação do desempenho académico do seu educando mais concretamente em relação às notas. $60 \%$ considerou que têm sido boas, $16,4 \%$ razoáveis, $9,1 \%$ muito boas, $1,8 \%$ más, ninguém considerou muito más e $12,7 \%$ não emitiu qualquer opinião a respeito.

\subsection{Racionalidades, capital cultural e ascensão social para os adolescentes}

As teorias das escolhas racionais postulam que os actores sociais são intencionais e orientados para objectivos e têm um conjunto de preferências ordenadas hierarquicamente. Os comportamentos colectivos são resultados das escolhas pessoais maximizadas segundo a utilidade que têm para os mesmos. Há, de certo modo, cálculo de custos e benefícios nos comportamentos que os actores adoptam [Ferreira et al: 246 à 287]. Uma das variantes da teoria das escolhas racionais é a sociologia da acção de Boudon. Para este autor [1995: 29-34], inspirado em Weber e Simmel, este paradigma é formado por dois princípios que são: o individualismo metodológico, segundo o qual, todo o fenómeno social é resultado das acções e comportamentos individuais; e o princípio da racionalidade pressupõe que qualquer fenómeno social, para que seja compreendido, deve-se encontrar as "razões válidas" que lhes deram origem.

Nesta perspectiva, segundo ainda o referido autor [id: 38-41] existem a racionalidade objectiva (em que o actor utiliza os meios que julga serem objectivamente mais correctos, atendendo o conhecimento que possui, para alcançar determinados objectivos), racionalidade subjectiva (o actor decide a partir de um ou vários princípios que pensa ser adequado ao problema colocado) a racionalidade cognitiva (o actor acredita que uma determinada teoria é explicativa e explicita para acção) e a racionalidade psicológica ( inclui as acções afectivas emocionais como resultado de crenças e paixões).

Segundo Bonnewitz [2003: 53-54] Bourdieu, inspirado nas teorias de Marx e Weber, definiu quatro tipos de capital: o económico ( constituído pelos diferentes factores de produção e pelo conjunto de bens económico), o cultural (conjunto de qualificações culturais transmitidas pela escola e pela família), o social ( conjunto de relações sociais que possui um indivíduo ou grupo e o simbólico (conjunto de rituais ligados a honra e o reconhecimento). Na esteira de Víctor Kajibanga [2003: 23], a escola deve criar capital cultural e uma pedagogia necessárias para o reconhecimento e inclusão social dos actores angolanos.

Vimos acima que apesar da maioria (67\%) dos adolescentes ter declarado que já assistiu pelo menos um programa que sirva para consolidar os seus conhecimentos escolares, constata-se que o assistem com pouca frequência (tabelas 2 e 3). A televisão é um poderoso meio de comunicação de massas que concorre, quantas vezes a frente, com a escola (tabelas 4 e 5). Que razões fazem com que os adolescentes não prestem muita atenção aos programas que sirvam de complemento e aprofundamento dos conteúdos escolares no bairro em estudo? 
Os adolescentes são uma categoria social que está em transição entre a infância e a fase adulta. Esta transição provoca, de certo modo, a conflitualidade com certas instituições que "dominaram" o processo de socialização na sua infância, pois pretende, assim, entrar em contacto e relacionar-se com um "novo mundo". A formação académica é daquelas obrigações familiares que lhe é imposta desde a tenra idade, em que ainda não tem conhecimento suficiente de muita coisa que o circunda. A televisão, com a diversidade e atractividade dos seus conteúdos, é menosprezado, ou pouco incentivado, pelos encarregados de educação.

Ao não prestarem muita atenção aos programas que lhe sirvam para consolidar a sua formação académica, isto se deve, de certo modo, pelo facto dos adolescentes, ao avaliarem os custos e benefícios deste procedimento, não estarem convencidos que os mesmos sejam tão importantes para a sua formação académica. De certo modo, a formação académica das pessoas, na realidade luandense, ainda não é vista por muitos actores como um factor de peso para a ascensão na hierarquia social.

Já vimos que os professores representam figuras com certo conservadorismo a absolutismo e a escola é das instituições que mais contribui par a reprodução social e cultural da sociedade. A partir dos finais da década de 1980, assistiu-se a uma degradação estrutural e funcional do processo de ensino-aprendizagem nas escolas de Luanda. Por outro lado, apesar de ter aumentado o número de pessoas diplomadas, incrementouse o sentimento de desvalorização da formação académica como critério de ascensão social do indivíduo. Para muitos, o capital social e económico da família e amigos tinham maior influência do que um capital cultural adquirido, sobretudo, através da escola. Ou seja, para o indivíduo ter acesso e ascender num "bom” emprego, habitação, regalias sociais, entre outros, bastava ser de família que pertencesse a determinado círculo próximos de estruturas de poder ou ter "amigos" bem colocados na hierarquia de determinadas instituições da administração pública e privada independentemente do seu grau académico ${ }^{15}$. Isto não significa que, necessariamente, os adolescentes desvalorizem completamente a continuidade da sua formação académica ${ }^{16}$.

Este sentimento de desvalorização do capital cultural adquirido através da formação académica, nos adolescentes, pode ser ainda devido o facto da maioria das pessoas que são os seus modelos de referência como as vedetas (e que são detentores de grande capital económico) como as do cinema, da música, da televisão não parecerem, aos seus olhos, como pessoas que tenham tido uma bem sucedida formação académica mas cujas

15 Embora o Governo angolano tenha feito algum esforço para que se aumentasse o número de pessoas com formação académica, o que se assistiu durante muitos anos é a não existência de uma política eficiente de enquadramento e valorização dos quadros recém-formados em função das suas áreas e competências profissionais.

16 Numa pesquisa realizada por Paulo de Carvalho em 1994 junto de 28 adolescentes estudantes de um instituto médio de Luanda, entre os 15 e 23 anos de idade, do $10^{\circ}$ e $11^{\circ}$ anos de escolaridade, verificase que entre os 28 estudantes que fizeram parte da pesquisa, 26 pretendiam concluir uma licenciatura [Carvalho 2002b: 141-151]. 
trajectórias se deverem tanto, aparentemente, ao seus talento e/ou oportunidades que tiveram no mercado de bens simbólicos.

A própria degradação do processo de ensino-aprendizagem que se foi assistindo nas escolas luandenses, em termos de estrutura física, de transmissão e avaliação dos conteúdos escolares e outros componentes, fizeram, também, com que o Sistema de Ensino caísse no descrédito. A dedicação aos estudos não parecia, de certo modo, representar um dos factores, de peso, para o sucesso escolar já que o nível de corrupção entre os seus agentes cresceu ${ }^{17}$. Com isto, a violência simbólica dos professores em relação aos alunos, em termos de transmissão e avaliação dos conhecimentos escolares fez com que, ao longo de duas décadas após a independência política, fosse desvalorizada a figura do docente, em particular, e da formação académica, em geral.

Já vimos acima concomitantemente que a precariedade do sistema de ensino, um dos meios de socialização que mais ganha espaço, na vida dos adolescentes, é a televisão. Ora, não estando os adolescentes convencidos que muitas referências que têm a partir da televisão não são de todo inútil, e não acreditamos que alguma vez tenha sido, ficam, nestes casos, mais propensos a sua influência.

Assim, os adolescentes preferem os programas de entretimento emitidos pela televisão como as telenovelas, os programas desportivos e os filmes de acção, não só pelos problemas estruturais e funcionais da escola e da pouca credibilidade que tinha, em termos de promoção e ascensão social do indivíduo, mas também devido ao forte apelo que tais programas fazem a afectividade, agressividade, ao sexo, as paixões, entre outros aspectos, que estão fortemente relacionados com as suas racionalidades. Isto faz com que os mesmos criem uma estrutura de pensamento, de percepção e de representações que lhes faça obter um capital cultural e social que lhes permita estar numa posição de vantagem no relacionamento com seus amigos, colegas namorado (a) e outros indivíduos, da mesma categoria social, que tenham de ter contactos esporádicos e permanentes. Como se pode constatar nas respostas descritas acima, os conteúdos assistidos pela televisão são maioritariamente objecto de conversa com amigos e colegas do que aquilo que é aprendido na escola. Como beijar, fazer os jogos afectivos e sexo, disputar uma luta física e defender-se dos perigos, vestir-se e falar duma forma juvenil são questões que estão no centro das suas preocupações mas que a escola e a família, devido a desregulamentação que tiveram no espaço urbano, não lhes dão abertura e respostas suficientes e a televisão as vai tornando cada vez mais expostas. Não se trata, assim, só de um problema de desvio em relação as práticas propaladas pelos adultos na escola e/ou na família, é também uma questão de integração e de sobrevivência no seio de uma subcultura adolescente.

17 Embora seja dificil mensurar nos últimos dois anos a dimensão do fenómeno, a melhoria dos salários dos docentes que houve nos últimos 5 anos e algumas medidas como campanhas denúncias públicas de combate e feitas pelo Ministério da Educação terão atenuado o fenómeno. 


\section{Conclusão}

Esta abordagem permitiu-nos verificar que de facto a televisão é um meio de comunicação de massa com grande influência nos adolescentes. Está a exercer pouca influência na formação académica dos adolescentes porque os docentes, especialistas de televisão e encarregados de educação ainda não reconhecem o papel que alguns conteúdos televisivos têm para complemento e aprofundamento do que é transmitido na escola, contribuindo, deste modo, para a sua formação académica. Consequentemente, o tempo de demasiada exposição aos programas de entretimento da televisão é inversamente proporcional ao êxito na formação académica desta categoria social.

Os limites, nesta abordagem, estão relacionados, entre outros aspectos, ao facto de não termos incluído a opinião dos docentes, não ter sido feita uma pesquisa mais aprofundada sobre a existência de aparelhos de televisão nas escolas em Luanda. Podia ainda ser feita, em próximos estudos, análise da questão explorando, correlacionarmente, variáveis como o nível e rendimento académicos, idade, sexo e condições de habitabilidade dos adolescentes em outros contextos geográficos de Luanda e de Angola.

\section{Referências Bibliográficas}

António, Manuel (2003), Um Olhar e Pensar Televisão, Luanda, Edições de Angola Balle, Francis (1995), "A Comunicação" in Boudon, Raymond (org) Tratado de

Sociologia. Lisboa, Asa, pp.515 - 539

Balle, Francis/Cazeneuve, Jean (s/d), "A Informação Colectiva e os Mass Media" in

Enciclopédia Sociológica Contemporânea, Porto, Rés Editora, pp.105 - 177

Bluwal, Marcel (1977), “Televisão, Informação e Formação” in A Escola e a Sociedade,

Lisboa, Estampa, pp. 47-53

Bourdieu, Pierre (1999), Sobre a Televisão, Oeiras, Celta

Breton, Philippe (1994), A Utopia da Comunicação, Lisboa, Instituto Piaget

Carpelli, Sérgio (1986), Comunicação de Massa sem Massa, S. Paulo 3 a edição, Summus

Carvalho, Paulo De (2002 a), Audiência de Media em Luanda, Luanda, Nzila

Carvalho, Paulo De (2002 b), "Valores e Aspirações de duas Turmas do Ensino Médio

Luandense" in Paulo de Carvalho Angola: Quanto Tempo Falta para Amanhã,

Oeiras, Celta, pp. 141-151

Coelho, Sebastião (1999), Angola: História e Estórias da Informação, Luanda, Executive Center Desbordes, Louis (1977), "Um Universo não Fechado" in A Escola e a Sociedade, Lisboa, Estampa, pp. 19-24

Fenwick, Elizabeth/Smith, Tony (1995), Adolescência: Um Valioso Guia para Pais e Adolescentes, Minho, Editora do Minho

Fernandez, M. Antónia (1993), “Comunicacion de Masa Y Cambio Politico: Analisis 
de una Campana Electoral" in Estrutura Social e Desenvolvimento: Actas do II

Congresso Português de Sociologia, Lisboa, Vol. I, Fragmentos e APS

Freixo, Manuel (2002), Televisão e a Instituição Escolar: os Efeitos Cognitivos das Mensagens

Televisivas e a sua Importância na Aprendizagem, Lisboa, Instituto Piaget

Gauquelin, Michel et al (1980), Dicionário de Psicologia, Lisboa e S. Paulo, Verbo, P.18.

Giddens, Anthony (2000 a), Sociologia, Lisboa, Fundação Calouste Gulbenkian,

PP. 439 - 479

Juan, Milagros Dominguez (1993), "Los Efectos de la Comunication en el Entorno

Social”. in Estrutura social e Desenvolvimento: Actas do II' Congresso Português de Sociologia, Lisboa, Vol. I, Fragmentos e APS, pp.187- 201

Kajibanga,Victor(2003), “Tradição,Educação e Dimensão Cultural de Desenvolvimento” in Kulonga: Revista das Ciências da Educação e Estudos Multidisciplinares, n²,

Luanda, Edições Kulonga

Marconi, Marina De A./Lakatos, Eva Maria (1986), Técnicas de Pesquisa: Planejamento e Execução de Pesquisas, Elaboração, Análise e Interpretação dos Dados, S. Paulo, Atlas

Mateus, Ismael (2006), "Cultura, Mídia e Informação" Comunicação apresentada no $I^{\circ}$

Simpósio sobre a Cultura Nacional realizado em Luanda em Setembro

Morin, Edgar (1998), Sociologia, Lisboa, Publicações Europa América.

Maroco, João (2003), Análise Estatística com Utilização do SPSS, Lisboa, $1^{\mathrm{a}}$ Edição

Edições Sílabos, PP. - 19 - 23, 32 - 35, 373 - 385

Popper, Karl/COUNDRY, John (1995), Televisão: Um Perigo para a Democracia, Lisboa, Gradiva

Oliveira, Maria Da Luz et al (1989), Sociologia, Lisboa, Texto

Oliveira, Pérsio Santos (2002), Introdução à Sociologia da Educação, S. Paulo, Ática, $3^{\mathrm{a}}$ edição

Rodrigues, Adriano Duarte (1990), Estratégias de Comunicação: Questão Comunicacional e Formas de Sociabilidade, Lisboa, Editorial Presença

Rodrigues, Adriano Duarte (1999), Comunicação e Cultura: A Experiência Cultural na Era da Informação, 2a edição, Lisboa, Editorial Presença

S/A (1977), "Uma Conversa com Pierre Emmanuel da Academia Francesa" in Escola e Sociedade, Lisboa, Estampa, pp. 65-72

Schmidt, Luísa (1993), "Publicidade versus Consumo: os Jovens Preferem as Colas" in Estruturas Sociais e Desenvolvimento: Actas do II Congresso Português de Sociologia, vol. II, Lisboa, Fragmentos e APS, pp.271 - 281

Shervokin, Y.A. (1982), Problemas Psicológicos de los Processos Masivos de Informacion, Havana, Política

Tiba, Içami (2003), Sexo e Adolescência, 10a Edição ,S. Paulo, Ática.

UNESCO (1971), Meios de Informação e Violência, Lisboa, Edições 70

UNESCO (1996), Relatório da Comissão Internacional sobre a Educação para o sec. XXI, 7a edição, Porto, Edições ASA 